\title{
O turismo de base comunitária no contexto de um empreendimento econômico solidário no Pantanal de Mato Grosso do Sul
}

\author{
Milton Augusto Pasquotto Mariani \\ Universidade Federal de Mato Grosso do Sul - Campo Grande - MS - Brasil \\ ORCID: https://orcid.org/0000-0001-9485-0150 \\ Bruno Diego Alcantara Cardozo \\ Universidade Federal de Mato Grosso do Sul - Campo Grande - MS - Brasil \\ ORCID: https://orcid.org/0000-0002-2729-9255 \\ Dyego de Oliveira Arruda \\ Centro Federal de Educação Tecnológica Celso Suckow da Fonseca - Valença - RJ \\ - Brasil \\ ORCID: https://orcid.org/0000-0002-9514-284X \\ Maurílio Barbosa de Oliveira da Silva \\ Universidade Estadual de Campinas - Limeira - SP - Brasil \\ ORCID: https://orcid.org/0000-0002-8498-3010
}

\section{Resumo}

O presente artigo tem como objetivo compreender, a partir de uma pesquisa qualitativa, o modo como a perspectiva do turismo de base comunitária pode se inserir na dinâmica de atuação de um Empreendimento Econômico Solidário (EES) localizado na cidade de Corumbá, no Pantanal de Mato Grosso do Sul. Como subterfúgio para a coleta de dados, foram realizadas entrevistas em profundidade com pessoas que integram o EES. As entrevistas foram gravadas e, posteriormente, transcritas. Para a análise e interpretação dos dados, foram empregadas técnicas de Análise Crítica do Discurso. Ademais, os textos decorrentes da transcrição das entrevistas foram submetidos ao software Iramuteq que, dentre várias possibilidades, permite com que sejam geradas nuvens de palavras com os termos mais recorrentes nos discursos das pessoas. Em suma, os resultados do artigo apontam que, no âmbito do EES estudado, o turismo de base comunitária, muito embora ainda não seja uma realidade no EES, revela-se enquanto uma atividade com significativo potencial de geração de ocupação e renda à pessoas historicamente subalternizadas no território, numa dinâmica coerente com os princípios de solidariedade, cooperação e fraternidade, que caracterizam o turismo comunitário e o próprio movimento de economia solidária. Por fim, deve-se ressaltar que os resultados do artigo apontam para a demanda de que o poder público e os demais negócios das cadeias de produção do turismo sejam 
O turismo de base comunitária no contexto de um empreendimento econômico solidário no Pantanal de Mato Grosso do Sul

protagonistas no desenvolvimento de estratégias e políticas que insiram os EES nos roteiros turísticos do território.

Palavras-chave: Turismo comunitário. Economia solidária. Desenvolvimento local. Mato Grosso do Sul.

\section{Community-based tourism in the context of a solidary economic enterprise in the Pantanal of Mato Grosso do Sul, Brazil}

\section{Abstract}

This article aims to understand, from a qualitative research, how the perspective of community-based tourism can be inserted in the dynamics of a Solidary Economic Enterprise (SEE) located in the city of Corumbá, in the Pantanal of the State of Mato Grosso do Sul, in the Brazilian Midwest. As a strategy for data collection, in-depth interviews were conducted with people who are part of the SEE. The interviews were recorded and transcribed. For the analysis and interpretation of the data, Critical Discourse Analysis techniques were used. In addition, the texts resulting from the transcription of the interviews were submitted to the Iramuteq software, which, among a series of possibilities, allows word clouds to be generated with the most recurring terms in people's speeches. In summary, the results of the article indicate that, in the scope of the SEE studied, community-based tourism, although not yet a reality in the SEE, reveals itself as an activity with significant potential to generate occupation and income for people historically subalternized in the territory, in a scenario coherent with the principles of solidarity, cooperation and fraternity, which characterize community tourism and the solidarity economy movement itself. Finally, it should be noted that the results of the article point to the demand that the government and other businesses in the tourism production chains be protagonists in the development of strategies and policies that insert the SEE in the tourist itineraries of the territory.

Keywords: Community tourism. Solidarity economy. Local development. Mato Grosso do Sul, Brazil.

\section{Turismo comunitario en el contexto de una empresa económica solidaria en el Pantanal de Mato Grosso do Sul, Brasil}

\section{Resumen}

Este artículo tiene como objetivo comprender, a partir de una investigación cualitativa, cómo la perspectiva del turismo comunitario puede insertarse en el desempeño de una Empresa Económica Solidaria (EES) ubicada en la ciudad de Corumbá, en el Pantanal del Estado de Mato Grosso do Sul, en el medio oeste de Brasil. Como subterfugio para obtener datos para el estudio, se realizaron entrevistas en profundidad con las personas que forman parte del EES. Las entrevistas fueron grabadas y transcritas. Para el análisis e interpretación de los datos, se utilizaron técnicas de Análisis Crítico del Discurso. Además, los textos resultantes de la transcripción de las entrevistas se colocaron en el software Iramuteq, que, entre una serie de posibilidades, permite generar nubes de palabras con los términos más recurrentes en los discursos. En resumen, los resultados del artículo indican que, dentro del alcance del EES estudiado, el turismo comunitario, aunque todavía no es una realidad en el EES, se revela como una actividad con un potencial significativo para generar ocupación e ingresos para las personas históricamente excluidas en el territorio, en una dinámica coherente con los principios de solidaridad, cooperación y fraternidad, que caracterizan el turismo comunitario y el movimiento de economía solidaria. Finalmente, cabe señalar que los resultados del artículo apuntan a la demanda de que las autoridades públicas y otras empresas de las cadenas de producción turística sean protagonistas en el desarrollo de estrategias y políticas que inserten los EES en las rutas turísticas del territorio. 
Palabras clave: Turismo comunitario. Economía solidaria. Desarrollo local. Mato Grosso do Sul, Brasil.

\section{Introdução}

A economia solidária representa um verdadeiro movimento, cujo propósito é permitir com que os indivíduos, uma vez organizados de forma autônoma e solidária, possam lutar contra as formas de opressão historicamente construídas tais como as opressões decorrentes da classe socioeconômica, do gênero, da raça e da própria constituição identitária dos sujeitos (LAVILLE, 2008).

Os Empreendimentos Econômicos Solidários (EES), em suma, perfazem organizações (sejam formais ou informais) que, além de gerar renda e ocupação a pessoas em alguma situação de vulnerabilidade socioeconômica, também permitem com que se valorize a cultura, o modo de vida e os princípios básicos que relegam cidadania às pessoas (ARRUDA; MARIANI, 2014).

Dentre os princípios basilares que caracterizam os EES é possível destacar (SINGER, 2002): (I) a autogestão, que implica em processos organizacionais nãohierarquizados, nos quais a tomada de decisão é feita em um contexto no qual todos os sujeitos opinam e deliberam acerca dos rumos da organização; (II) a democracia, que perfaz um verdadeiro valor nos EES, relacionado à necessidade de constante diálogo entre os sujeitos; (III) a solidariedade, relacionada com o pleno sentimento de empatia e união entre as pessoas nas organizações; (IV) a cooperação, que decorre em ações de ajuda mútua e colaboração entre as pessoas envolvidas nos EES e; $(V)$ o comércio, consumo e remuneração justos, nos quais os bens e serviços decorrentes dos EES são precificados a partir de uma lógica que valoriza o trabalho e o saber-fazer inerente à esses itens, numa dinâmica em que a receita auferida da comercialização de bens e serviços é repartida de modo igualitário e justo entre os integrantes dos EES.

Depreende-se que os EES, a partir dos princípios que lhe são característicos, podem representar caminhos para a potencial superação da dinâmica socioeconômica excludente e desigual do sistema capitalista, que não raro estrutura-se a partir de princípios ligados à centralização de poder, à falta de solidariedade e cooperação entre pessoas, sem contar as eventuais injustiças na comercialização, consumo e remuneração pelos bens e serviços produzidos a partir de uma lógica eminentemente capitalista (GAIGER, 2003; SINGER, 2002).

Algumas atividades socioeconômicas - tais como o Turismo de Base Comunitária (TBC) - podem representar caminhos potenciais para que, por intermédio da difusão dos EES, haja um processo contínuo de inclusão social, solidariedade, cooperação e, por conseguinte, melhoria da qualidade de vida das pessoas, tanto visitantes quanto trabalhadores do segmento de turismo (SILVA; JESUS, FONSECA, 2011).

O Turismo de Base Comunitária (TBC) - ou simplesmente turismo comunitário representa um contraponto em relação à lógica massificada e homogeneizante do turismo convencional, de tal modo que os potenciais visitantes são conclamados a experimentar detalhes do modo de vida, costumes, crenças e hábitos das comunidades locais, partindo da perspectiva da plena alteridade e respeito à cultura 
dos territórios e das próprias comunidades receptoras (MANO; MAYER; FRATUCCI, 2017).

É possível considerar que as práticas de turismo comunitário, quando empreendidas de modo autônomo e solidário pelas comunidades, possuem a particularidade de serem mecanismos para: (I) estimular as dinâmicas de desenvolvimento endógeno nos territórios (CORIOLANO; VASCONCELOS, 2013); (II) contribuir com a sustentabilidade e, portanto, com a manutenção do meio ambiente, valorização da cultura e geração de renda nas comunidades receptoras (GRIMM, SAMPAIO, 2016); (III) permitir com que os turistas tenham experiências mais autênticas e transformadoras (ZAOUAL, 2008) e; (IV) fomentar, nos territórios, ações de cunho colaborativo, solidário e autogerido, não raro por intermédio dos empreendimentos da economia solidária (ARRUDA; MARIANI; FISCHER, 2013).

Para que o turismo comunitário seja efetivamente empreendido nos territórios é crucial que os EES, além de estarem inseridos nos sistemas solidários de turismo, também compreendam o potencial e a importância de tal tipo de atividade, tendo como escopo oferecer experiências turísticas que sejam singulares, transformadoras, solidárias e impactantes para os territórios e comunidades (SILVA; JESUS, FONSECA, 2011; BURGOS; MERTENS, 2016).

De todo modo, uma pergunta que neste momento surge é a seguinte: de que modo a perspectiva do turismo comunitário é compreendida e, eventualmente, implementada pelos EES em territórios turísticos?

Partindo da supracitada problemática de pesquisa, o presente artigo tem como objetivo geral compreender os dilemas e potencialidades da implementação de iniciativas de turismo comunitário a partir de um EES localizado no Pantanal do Estado de Mato Grosso do Sul.

Vale salientar que o pantanal sul-mato-grossense é um importante destino turístico do Centro-Oeste brasileiro, numa dinâmica em que a cidade de Corumbá revela-se como o principal ponto de apoio às práticas de turismo de pesca, contemplação e ecoturismo empreendidas no território pantaneiro (OLIVEIRA et al, 2008).

Entende-se que é salutar o esforço de análise das relações entre turismo comunitário e economia solidária, uma vez que uma incorporação ativa dos princípios e características do turismo comunitário pelos EES, somado à inserção plena desses empreendimentos nas cadeias produtivas de turismo dos territórios, podem representar importantes caminhos para a difusão de uma dinâmica de desenvolvimento endógeno nos territórios, melhorando a qualidade de vida e, de alguma forma, empoderando os grupos e comunidades envolvidos nesses esforços.

\section{0 contexto e princípios do turismo comunitário}

O Turismo de Base Comunitária (TBC) representa o conjunto de práticas turísticas que decorrem da participação plena dos grupos comunitários, que no geral colocam-se como os protagonistas dos processos de gestão e difusão de tais iniciativas nos territórios turísticos, partindo de princípios ligados à solidariedade e cooperação entre os sujeitos (BARTHOLO, 2009).

No âmbito do TBC considera-se que as próprias especificidades socioculturais, a culinária típica, os costumes, os hábitos, as crenças populares, além dos recursos 
ambientais dos territórios representam os grandes ativos para a formatação e difusão de produtos ligados ao turismo comunitário, no geral direcionados à um turista consciente da necessidade de uma postura de respeito ante às rotinas próprias dos territórios a serem visitados (LIMA, 2011). Além disso, vale citar que os turistas interessados na lógica do TBC são aqueles que veem o turismo enquanto fonte de experiências que sejam impactantes e memoráveis, tanto para eles próprios quanto para as comunidades com as quais interagem (ASSIS; PEIXOTO, 2019).

O Ministério do Turismo (MTur), ao estruturar estratégias e políticas públicas de fomento às iniciativas de $T B C$, reconhece que tal prática é significativamente contemporânea e multidisciplinar, numa dinâmica em que é complexo o esforço de delimitar, de modo contundente, os princípios característicos do turismo comunitário. De todo modo, o MTur ressalta que as conceituações mais corriqueiras acerca do Turismo de Base Comunitária sugerem que os princípios que caracterizam essas iniciativas são (BRASIL, 2010, p. 16): (a) autogestão; (b) associativismo e cooperativismo; (c) democratização de oportunidades e benefícios; (d) centralidade da colaboração, parceria e participação; (e) valorização da cultura local; e (f) protagonismo das comunidades locais na gestão da atividade e/ou na oferta de bens e serviços turísticos, visando à apropriação, por parte destas comunidades, dos benefícios advindos do desenvolvimento da atividade turística.

Fabrino, Nascimento e Costa (2016, p. 176), após uma exaustiva revisão da literatura já publicada, salientam que o turismo comunitário é caracterizado pelos seguintes elementos: (a) dominialidade (magnitude em que a própria comunidade controla as propriedades e faz a gestão dos produtos turísticos); (b) organização comunitária; (c) democratização de oportunidades e repartição de benefícios; (d) integração econômica (relação do turismo comunitário com outras atividades econômicas existentes no território); (e) interculturalidade (magnitude do intercâmbio cultural entre os visitantes e a comunidade local); e (f) qualidade ambiental (alusiva às formas de manejo e conservação dos ativos naturais existentes no território). Os mesmos autores supracitados, após uma investigação empírica de experiências de turismo comunitário no Ceará, concluem que os elementos "dominialidade" e "organização comunitária" são centrais, de tal modo que os elementos restantes podem ser compreendidos como consequências das práticas efetivas de turismo de base comunitária no território.

No âmbito do TBC, vale dizer que os processos de gestão e difusão das iniciativas partem de princípios solidários e democráticos, nos quais os benefícios de tal atividade recaem sobre toda a comunidade (HIGGINS-DESBIOLLES, 2008). Nesse ínterim, Giampiccoli e Mtapuri (2015) ressaltam que as iniciativas de TBC buscam a promoção do auto-planejamento, autossuficiência e autogestão, numa dinâmica em que as práticas de turismo comunitário devem ser transformadoras, redistributivas, capacitadoras e, portanto, geradoras de desenvolvimento para os territórios.

Zaoual (2008), além de Burgos e Mertens (2016) lembram que o turismo comunitário, contemporaneamente, posiciona-se enquanto um verdadeiro contraponto em relação ao turismo de massa, pós-industrial, cuja lógica remonta à uma verdadeira padronização e consumo exacerbado dos ativos socioambientais dos territórios. Nesse ínterim, pode-se depreender que as iniciativas de TBC, tal como o movimento de economia solidária, podem representar um verdadeiro 
contraponto em relação às lógicas eminentemente excludentes dos modelos de negócios típicos do modo de produção capitalista (GAIGER, 2003; BARTHOLO; SANSOLO; BURSZTYN, 2009).

Além disso, Zaoual (2008) ressalta ainda que a prática de TBC possibilita com que o visitante tenha experiências eminentemente autênticas, numa dinâmica em que tais experiências permitam com que os visitantes conheçam melhor a si próprios a partir da interação com o outro, numa lógica calcada na alteridade.

De todo modo, vale salientar que não é um expediente fácil planejar e gerir iniciativas de turismo comunitário, tanto no Brasil como em outros destinos turísticos ao redor do mundo. No geral, os principais fatores que podem representar a derrocada das ações de TBC são as seguintes (MIELKE; PEGAS, 2013): (I) dificuldades de acesso ao mercado, relacionadas principalmente à inexistência de ações programáticas de divulgação dos produtos do turismo comunitário; (II) problemas de governança interna, principalmente no que tange à dificuldade de agir coletivamente e de modo solidário no âmbito das organizações de turismo comunitário; (III) dificuldades na gestão de parcerias estratégicas de interesse, sobretudo com organizações já estabelecidas no chamado "trade turístico" (tais como grandes redes de hotéis, restaurantes, agências e operadoras de turismo nos territórios).

É importante que as iniciativas de turismo comunitário estejam, de alguma forma, integradas nas cadeias produtivas do turismo - que envolvem o conjunto de atores direta ou indiretamente responsáveis pelo planejamento e operacionalização da atividade turística nos territórios (BENI, 2020). Além disso, vale dizer que é papel dos gestores públicos a incorporação do turismo comunitário nas políticas públicas; ao passo que é função das organizações que operacionalizam o turismo (tais como as agências e operadoras de turismo, hotéis e afins) a inserção das iniciativas de TBC no rol de opções e produtos dos territórios turísticos (OLIVEIRA; SANTOS, 2019).

Silva, Jesus e Fonseca (2011), ao refletirem acerca da lógica e características do turismo comunitário, sugerem que os Empreendimentos Econômicos Solidários (EES) podem ser importantes protagonistas da difusão das iniciativas de TBC desde que sejam bem planejados e difundidos. Ainda segundo os autores, os EES trazem na sua gênese os princípios da solidariedade organizativa, democracia, autogestão e justiça social, numa dinâmica em que tais aspectos potencialmente permitem com que a lógica que sustenta o turismo comunitário - também calcada na alteridade, respeito mútuo e solidariedade - seja mais facilmente alcançada e oferecida aos potenciais visitantes dos territórios.

Porém, quais os aspectos característicos da economia solidária e, mais particularmente, dos EES? No tópico que segue há um esforço de se discutir tais questões.

\section{A economia solidária e os EES em perspectiva analítica}

A economia solidária, em síntese, representa um movimento cuja origem remonta ao próprio esforço de organização e luta dos trabalhadores, que sobretudo na segunda metade do século XX viram-se alijados dos ciclos contemporâneos de acumulação e (re)produção do capital (SINGER, 2002). 
Nesse ínterim, Lima (2004) salienta que o fenômeno da globalização, a intensa mecanização e automatização dos processos de trabalho, além da diminuição da abrangência de direitos sociais básicos fizeram, no correr do século $\mathrm{XX}$, com que muitos trabalhadores perdessem a sua fonte de renda e subsistência, numa dinâmica em que tais sujeitos foram direcionados, quase que compulsoriamente, às formas de organização e produção características da economia solidária.

Desse modo, percebe-se que o movimento de economia solidária surge nos territórios mais precarizados e pobres, nos quais as populações historicamente marginalizadas (tais como pessoas pobres, negras, indígenas, mulheres e imigrantes) organizaram-se em empreendimentos nos quais pudessem encontrar apoio, dignidade, solidariedade e fontes de subsistência (MAZA, 2016; HILLENKAMP, 2019).

Arruda e Mariani (2013) lembram que há duas perspectivas a partir das quais é possível compreender o movimento de economia solidária: (I) enquanto um conjunto de iniciativas que representa um primeiro passo no sentido da superação dos desígnios excludentes do sistema capitalista (tal perspectiva é fortemente ligada à referenciais epistemológicos marxistas) e; (II) como um conjunto de estratégias, não raro passíveis de serem estimuladas pelo conjunto das políticas públicas, que perfazem formas inovadoras de organização produtiva e geração de ocupação e renda, que subsistem concomitantemente com as formas características de produção e consumo do sistema capitalista.

Do ponto de vista prático, os Empreendimentos Econômicos Solidários (EES) podem assumir as seguintes configurações (GAIGER, 2006): associações comunitárias de produtores e/ou consumidores de bens e serviços das mais diversas ordens; grupos de catadores de materiais recicláveis; fábricas de pequeno porte, não raro recuperadas pelos próprios trabalhadores, organizados sob a batuta da autogestão; além de cooperativas e grupos nos quais são comungados princípios ligados à solidariedade e comunhão.

Vale registrar que os EES, além de serem passíveis do apoio das políticas públicas, também encontram suporte em movimentos da sociedade civil organizada, tais como os movimentos religiosos, culturais, de trabalhadores (incluindo os sem-terra e os sem-teto), étnico-raciais, de gênero, além dos movimentos ligados à questões ambientais (FRANÇA FILHO; LAVILLE, 2006).

Nesse ínterim, deve-se ponderar que a economia solidária perfaz um conjunto de iniciativas que surgem no escopo dos grupos subalternizados e invisibilizados nas sociedades contemporâneas, de modo a permitir alguma possibilidade de (re)existência, emancipação e afirmação identitária por parte desses sujeitos subalternos, conforme nos lembra Gayatri Spivak (2010).

O movimento de economia solidária no Brasil, a despeito de ter surgido no começo da segunda metade do século XX, só ganhou status de política de governo nos idos de 2003, com a criação e institucionalização da Secretaria Nacional de Economia Solidária (SENAES), uma autarquia ligada ao Ministério do Trabalho e Emprego cujo propósito era gerar ocupação e renda à grupos organizados, em situação de alguma vulnerabilidade socioeconômica (GOULART; MARIN, 2011). Contemporaneamente, percebe-se que a economia solidária não mais representa uma política relevante e prioritária de governo, de tal modo que a SENAES, a despeito de ainda existir formalmente, foi rebaixada ao status de mero 
departamento dentro da estrutura organizacional do atual Ministério da Cidadania que não possui agendas programáticas para o fomento e difusão de EES.

Segundo os últimos mapeamentos feitos acerca da configuração dos EES no Brasil, publicados em 2016 pelo Instituto de Pesquisa Econômica Aplicada (IPEA, 2016), nota-se que atualmente existem no país 19.708 empreendimentos, distribuídos em mais de 2.700 municípios brasileiros, numa dinâmica em que a significativa maioria dos EES mapeados (40,8\% do total) localizam-se na região Nordeste - uma área significativamente precária, com indicadores que revelam um quadro endêmico de pobreza e desigualdade socioeconômica, de tal modo que tais dados corroboram com a perspectiva de Maza (2016) e Hillenkamp (2019), citados neste tópico, que dão conta de que os EES normalmente surgem nos próprios territórios precarizados e mais vulneráveis.

O mapeamento conduzido pelo IPEA ainda dá conta das seguintes características e dimensões socioestruturais dos EES brasileiros (IPEA, 2016):

(I) A grande maioria dos EES (quase $57 \%$ do total) estão ligados à produção e comercialização de bens e serviços, a maioria feita de modo artesanal. Tal constatação revela a preponderância dos EES enquanto fonte de renda e subsistência às pessoas que fazem parte desse tipo de iniciativa;

(II) Pouco mais de $65 \%$ dos EES brasileiros surgiram a partir dos anos 2000, sobretudo na época em que havia uma agenda programática de políticas públicas, capitaneadas pela SENAES, que estimulava esse tipo de empreendimento;

(III) A maioria dos EES (54,8\% do total) perfazem iniciativas cuja área de atuação é o perímetro rural dos municípios. Os EES eminentemente urbanos são 10,4 \% do total - os outros $34,8 \%$ são mistos, ou seja: atuam tanto na área rural quanto no perímetro urbano;

(IV) Percebe-se que 60\% dos EES mapeados no Brasil configuram-se enquanto associações de produção e comercialização de bens e serviços. Significativos 30,5\% dos EES perfazem grupos informais, não raro estruturados a partir de um quadro organizativo e institucional mais precário;

(V) A maioria dos EES mapeados são corporificados por homens (são quase $57 \%$ do total de pessoas envolvidas nessas iniciativas). De todo modo, chama a atenção o fato de que as mulheres são a maioria (63,2\% do total) nos EES que se classificam enquanto grupos informais;

(VI) No geral, a expressa maioria dos EES possui baixo faturamento e carecem de capital de giro, estrutura de transporte, além de melhores condições para a comercialização dos bens e serviços produzidos no âmbito do empreendimento.

Gaiger e Kuyven (2020) lembram que, a despeito da importância e do fato de a economia solidária ter sido pauta de agendas de políticas públicas no passado recente, é crucial frisar que, contemporaneamente, com o advento de governos ultraliberais e conservadores no Brasil e em boa parte da América do Sul, o movimento de economia solidária sobrevive de forma precária, não raro ainda ancorado e catalisado pelas iniciativas da sociedade civil organizada e dos próprios sujeitos subalternizados que são impactados pelos EES.

Conti e Antunes (2020), ao analisarem a perspectiva do turismo comunitário e da economia solidária, salientam que ambos os movimentos possuem características e 
princípios muito similares, o que - potencialmente - poderia permitir uma atuação conjunta e coordenada, com os EES tomando as rédeas no oferecimento de bens, serviços e experiências ligadas ao TBC. Porém, os autores em tela salientam que, enquanto os EES tiveram, no passado recente, políticas públicas de fomento, o turismo comunitário sempre esteve à margem das políticas de estímulo ao turismo no Brasil, de tal modo que tal assimetria na institucionalização de agendas de políticas públicas pode ser um dos aspectos que fez com que ambos os movimentos - do turismo comunitário e da economia solidária - não sejam, na prática, tão evidentes, sinérgicos e expressivos.

Vale citar, por ser oportuno, que Conti, Rocha e Viteze (2018) pontuam que em muitas circunstâncias, na prática, o turismo comunitário não é plenamente compreendido e assimilado nas ações típicas do movimento de economia solidária e, particularmente, dos EES. Desse modo, percebe-se que são urgentes as investigações - tal como a capitaneada no presente estudo - que tenham como escopo a compreensão dos dilemas em torno da implementação de iniciativas de turismo comunitário no âmbito da atuação dos EES em territórios turísticos.

\section{Delineamentos metodológicos da pesquisa}

Quanto ao processo de investigação, a abordagem empregada no estudo é qualitativa, compreendida como o método mais subjetivo e que envolve o exame e a reflexão sobre as percepções dos sujeitos, tendo como propósito a plena compreensão dos contextos humanos e sociais (CRESWELL, 2010).

Além disso, a pesquisa define-se como descritiva e analítica. A abordagem descritiva justifica-se em função do interesse em caracterizar o comportamento dos fenômenos do turismo comunitário e da economia solidária, no âmbito de um Empreendimento Econômico Solidário (EES) específico, localizado no Pantanal do Estado de Mato Grosso do Sul, mais precisamente na cidade de Corumbá. Não obstante, a pesquisa é analítica porque busca ir além da mera descrição das características dos fenômenos, analisando e explicitando o porquê ou como eles acontecem. Dessa forma, busca-se entender fenômenos, descobrindo e avaliando relações causais entre eles (COLLIS; HUSSEY, 2005).

Vale dizer que a presente investigação também se classifica como um estudo de caso, uma vez que tem como escopo descortinar, em detalhes, o modo como um ESS em específico, localizado na cidade de Corumbá, no Pantanal sul-matogrossense, incorpora preceitos do turismo comunitário no âmbito da própria gênese e atuação do empreendimento. Logo na sequência, no começo da análise de resultados deste artigo, as características fundamentais do EES estudado serão descritas.

Ao longo da apresentação e discussão dos resultados do estudo, optou-se por não explicitar o nome do EES analisado, bem como das pessoas com as quais se estabeleceu interação ao longo da coleta de dados. Nesse ínterim, esta pesquisa segue os preceitos de Padilha et al. (2005), pois garante o anonimato, a privacidade e a proteção da imagem do empreendimento, além de assegurar o respeito aos valores culturais, religiosos e morais dos participantes.

Como instrumento de coleta de dados, foram realizadas entrevistas com as pessoas que participam do EES investigado. As entrevistas foram conduzidas a 
partir de um protocolo contendo questões norteadoras, cujo propósito fundamental era: (I) compreender a história e origem do empreendimento; (II) descortinar as características fundamentais do modo de organização e da estrutura do EES; (III) revelar o modo como a atividade do turismo comunitário "se insere" no escopo de atuação do empreendimento e; (IV) explicitar as principais lacunas do EES, além do modo como o empreendimento relaciona-se com as políticas públicas e com o próprio poder público. Ressalte-se que todas as entrevistas foram gravadas e, posteriormente, transcritas. Ademais, vale pontuar que as entrevistas foram plenamente consentidas pelas pessoas que participam do EES, que assinaram um Termo de Consentimento Livre e Esclarecido (TCLE), no qual havia a descrição de todos os detalhes da pesquisa.

Uma particularidade que merece vir à tona é o fato de que o EES selecionado como "caso" deste estudo é um empreendimento que, stricto sensu, é reconhecido como solidário pelos mapeamentos realizados no âmbito da Secretaria Nacional de Economia Solidária (SENAES). Além disso, vale dizer que o EES é (re)conhecido no território do Pantanal de Corumbá, não raro sendo citado como detentor de grande potencial para a produção e comercialização de bens e serviços no âmbito do turismo comunitário.

Como subterfúgio para a análise das entrevistas conduzidas, optou por utilizar a Análise Crítica do Discurso (ACD), nos moldes propostos por Van Dijk (1980, 1987 e 1998), que sugere que o discurso, do modo como é “construído", com todas as relações de poder a ele inerentes, pode ser um relevante caminho para a compreensão da estrutura das organizações e da própria sociedade.

A ACD, neste estudo, foi utilizada partindo da perspectiva de que o exercício de fala dos entrevistados possui um domínio definido por três aspectos fundamentais (VAN DIJK, 1998): (I) o discurso, que é o evento comunicativo em si, quem além de trazer a perspectiva da fala também é um caminho de expressão corporal e facial; (II) a cognição, que perfaz o modo como os sujeitos articulam os argumentos, não raro a partir de emoções, crenças e costumes partilhados pela comunidade e; (III) a sociedade, que "manifesta-se" por intermédio do sujeito através de relações de poder entre grupos sociais e, por conseguinte, na naturalização de determinadas crenças e costumes. O exercício analítico, neste artigo, foi tentar compreender os detalhes e estratagemas em torno do discurso das pessoas que participam do EES investigado; discurso este que carrega um conjunto de crenças e percepções comungadas pelos membros do território no qual o EES se localiza.

Por fim, como subterfúgio para a análise das entrevistas (que, por terem sido muito profícuas, geraram um significativo volume de textos transcritos), utilizou-se um software livre chamado Iramuteq, que se refere à uma ferramenta que viabiliza diferentes tipos de análise de dados textuais, desde aquelas bem simples, como a lexicografia básica (cálculo de frequência de palavras), até análises multivariadas, possíveis em função de o Iramuteq ser ancorado no $\mathrm{R}$, um software estatístico (CHARTIER; MEUNIER, 2011).

Vale dizer que no âmbito do presente artigo utilizou-se a nuvem de palavras, elaborada pelo Iramuteq. Em suma, a nuvem de palavras representa uma espécie de diagrama em que as palavras mais recorrentes, ao longo do discurso das pessoas entrevistas, aparecem com maior destaque. A partir dos principais termos da nuvem 
de palavras realizou-se todo o esforço de compreensão dos detalhes do discurso dos/as entrevistados/as, à ótica das perspectivas da Análise Crítica do Discurso.

\section{As principais questões em torno do caso e do contexto estudados}

O processo de análise e interpretação dos resultados que sustentam as reflexões deste artigo está, para fins didáticos, divido em três tópicos principais: (I) a apresentação das características gerais de Corumbá, território no pantanal sulmato-grossense no qual se localiza o EES estudado; (II) a descrição da origem e estrutura geral do EES e; (III) a compreensão do modo como a perspectiva do turismo comunitário "se insere" na gênese e atuação do EES sob análise.

\subsection{Características gerais de Corumbá, no Pantanal de Mato Grosso do Sul}

Corumbá é um município localizado no extremo oeste de Mato Grosso do Sul, distante pouco mais de 420 quilômetros de Campo Grande, a capital do Estado. Vale dizer que o território de Corumbá faz divisa com a cidade boliviana de Puerto Quijarro, numa dinâmica que faz com que a localidade sob análise seja permeada por um intenso trânsito de pessoas e, por conseguinte, de culturas muito peculiares.

Segundo dados do IBGE (2019), a população absoluta de Corumbá está estimada em pouco mais de 111 mil pessoas, distribuídas em 64 mil km² de área - o que resulta em uma densidade demográfica de pouco mais de 1,7 habitantes por $\mathrm{km}^{2}$ de área. Ainda de acordo com os dados do IBGE (2019), a cidade de Corumbá apresenta o seguinte panorama socioeconômico:

(I) O PIB per capita do município, considerando dados relativos à 2017, foi de $\mathrm{R} \$$ 26.107,73 - valor significativamente inferior em relação ao PIB per capita do Mato Grosso do Sul (que em 2017 foi de $\mathrm{R} \$$ 35.520,45), e em relação ao próprio PIB per capita brasileiro, que no mesmo período foi de $\mathrm{R} \$ 31.833,50$. Tais dados, notadamente, revelam um quadro de um poder aquisitivo, em Corumbá, inferior em relação à conjuntura regional e nacional;

(II) O percentual de pessoas ocupadas em Corumbá, em relação à população absoluta do município, é de $14,2 \%$ - valor significativamente menor em relação aos mais de $60 \%$, que é a taxa relativa à população ocupada do Estado de Mato Grosso do Sul;

(III) O percentual da população corumbaense com rendimento nominal mensal de até meio salário mínimo é de 37,6\%;

Em síntese, uma análise rápida da conjuntura sociodemográfica de Corumbá revela que o município é corporificado por pessoas que, em média, possuem baixos níveis de renda e poucas oportunidades de ocupação, numa dinâmica em que as atividades informais e precárias são muito comuns no município. Nesse ínterim, percebe-se que a conjuntura sociodemográfica de Corumbá impulsiona as pessoas a migrarem para alternativas ligadas ao movimento de economia solidária, que é especialmente impulsionado em contextos de significativo desemprego e precariedade socioeconômica, conforme nos lembraram Singer (2002), Maza (2016) e Hillenkamp (2019), citados ao longo do referencial teórico deste artigo. 
Um aspecto acerca de Corumbá que merece vir à tona neste tópico é fato de que o município sob análise é (re)conhecido nacionalmente como a "capital do Pantanal", visto que se localiza em uma área completamente cercada pelo bioma pantaneiro - mais de $60 \%$ do Pantanal sul-mato-grossenses e $37 \%$ do Pantanal brasileiro estão localizados em uma extensão territorial que pertence à cidade de Corumbá (CÂMARA DOS DEPUTADOS, 2008). Não obstante, o município possui uma vasta área (que inclui o próprio perímetro urbano corumbaense) que é margeada pelo Rio Paraguai, um importante corredor hidroviário do território, que permite o escoamento de minérios e produtos agrícolas do Centro-Oeste brasileiro para os mercados consumidores da América do Sul e até da Europa e Ásia (DNIT, 2018).

No que tange ao turismo, vale dizer que o território de Corumbá é um importante destino ligado ao turismo de pesca no Rio Paraguai e nos seus respectivos afluentes. Nesse ínterim, a grande maioria dos integrantes do trade turístico do território (o que inclui as agências e operadoras de turismo, além dos hotéis e barco-hotéis) estruturam-se para oferecer alternativas de produtos turísticos eminentemente ligados à temática da pesca. Ademais, as próprias políticas de turismo no município e no Estado de Mato Grosso do Sul possuem o propósito de estimular a lógica do turismo de pesca no território, uma vez que há uma crença naturalizada de que tal segmento de turismo é a grande fonte potencial de geração de renda e ocupação na localidade (MACHADO; COSTA, 2017).

Uma análise acerca da configuração do turismo em Corumbá dá conta de que é passível de críticas o modo como tal atividade é estruturada e "pensada" no território, principalmente porque os roteiros e "pacotes" normalmente oferecidos aos turistas implicam em pouco contato dos visitantes com os elementos culturais, paisagísticos, históricos e arquitetônicos do território - normalmente, o turista que chega em Corumbá, seja por via aérea ou terrestre, é direcionado para um barcohotel, no qual fica dias navegando pelo Rio Paraguai, envolvido na prática da pesca esportiva; não há, desse modo, uma preocupação em oferecer outras possibilidades de se "fazer turismo" no território, mesmo que de forma complementar ao turismo de pesca (FAGUNDES; SCHMIDT; CENTURIÃO, 2013).

A despeito da ênfase no turismo de pesca, deve-se ressaltar que o território de Corumbá possui outras possibilidades de práticas turísticas, principalmente ligadas ao ecoturismo, turismo de contemplação da fauna e flora pantaneiras, turismo cultural, turismo arquitetônico (visto que a constituição histórica de Corumbá é muito pitoresca, numa dinâmica em que a fundação do município data de 1778), turismo étnico (que abranja as populações quilombolas e ribeirinhas, que são muito comuns no território), além - é claro - do próprio turismo comunitário, originado de modo solidário e participativo, enquanto um verdadeiro contraponto em relação ao mainstream que o turismo de pesca representa na localidade.

E como os EES, eventualmente, inserem-se na dinâmica do turismo em Corumbá, ao incorporarem a lógica do turismo comunitário que pode ser desenvolvido no território? Antes de refletir em torno da supracitada questão, há uma caracterização, no subtópico que segue, do EES que foi considerado no estudo de caso deste artigo. 


\subsection{O EES em estudo: características gerais}

O EES escrutinado neste artigo foi fundado e registrado em 2003, na esteira das políticas públicas de fomento aos empreendimentos solidários; políticas estas que na época foram importantes, mas que contemporaneamente não mais se encontram em execução. Atualmente, o EES é composto por 13 mulheres, todas com alguma relação com a temática da pesca, que possui uma dimensão cultural e simbólica para os habitantes de Corumbá - as mulheres com as quais dialogamos são, elas próprias, pescadoras, além de esposas e/ou filhas de pescadoras/es. A atividade central do EES é a produção e comercialização de produtos artesanais feitos a partir do couro de peixe (normalmente de Tilápia), dos quais se destacam: colares, brincos, chaveiros, bolsas, cintos, chinelos e até vestimentas, todos com cores muito vibrantes e com uma estética ligada à temática do peixe, do pantanal, além das menções à cultura ribeirinha, negra e até indígena, conforme é possível ver na figura 1.

Figura 1 - Itens produzidos e comercializados pelo EES em análise
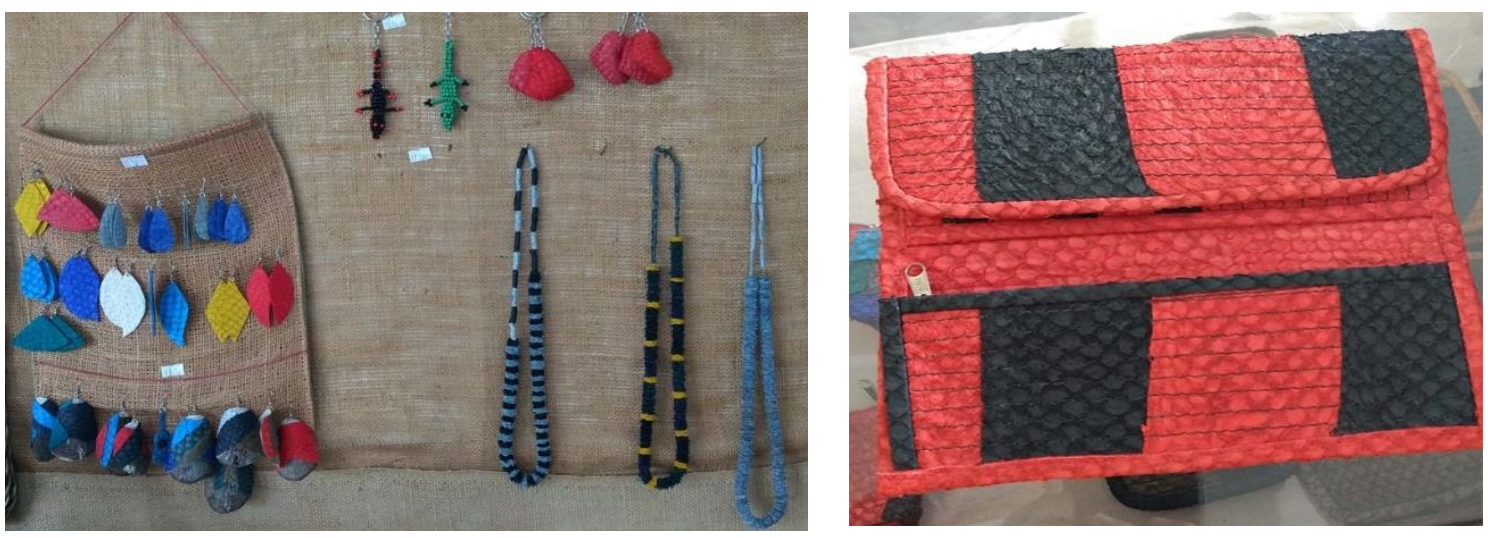

Fonte: Registros dos pesquisadores

Ao explorarmos o motivo pelo qual o EES resolveu estruturar-se para trabalhar com o couro do peixe, foi possível perceber que tal direcionamento veio do desejo de reaproveitar um subproduto da pesca - normalmente, o couro do peixe era descartado, dado que não havia uma compreensão do valor intrínseco a tal produto, antes do surgimento do empreendimento. $O$ conhecimento acerca dos métodos para o curtimento e manuseio do couro do peixe veio de um curso, feito em 2001 no SENAC (Serviço Nacional de Aprendizagem Comercial), por uma das pessoas que ainda atua no empreendimento. Além disso, a compreensão acerca dos princípios e características da atuação solidária, cooperativa, democrática e autogestionária do EES veio também de cursos feitos pelas pessoas que ainda corporificam o empreendimento sob análise.

O local em que o EES está sediado é a Casa do Artesão de Corumbá (CAC), em um espaço cedido pela prefeitura, no qual há a concentração das atividades de produção e comercialização dos itens feitos pelas mulheres do EES sob análise. Em suma, a CAC localiza-se em um local significativamente privilegiado, próximo do centro de Corumbá (onde estão importantes bares, restaurantes e hotéis da cidade) 
e do próprio Porto Geral do município, que é um espaço já turistificado, no qual as embarcações ligadas ao turismo de pesca ficam ancoradas, no Rio Paraguai.

Além da venda direta na própria Casa do Artesão de Corumbá, destaque-se que o EES investigado também comercializa os produtos por intermédio da participação em feiras e exposições (inclusive em outros Estados), bem como por meio de contatos feitos via WhatsApp, muitos deles decorrentes do "boca-a-boca", ou seja: na medida em que algum/a cliente compra os produtos e gosta, há um exercício de se recomendar esses itens para outras pessoas, o que em muitas circunstâncias acaba ampliando o nível de demanda dos itens feitos pelo EES. Vale dizer que, à ótica das mulheres do EES, a falta de parcerias, sobretudo com o poder público, faz com que, atualmente, a demanda pelos itens produzidos pelo EES fique muito aquém do desejável (a escassez de parcerias impede, por exemplo, com que as integrantes do EES participem de um maior número de feiras e exposições - que são espaços relevantes de comercialização).

Porém, muito embora os itens feitos pelo EES sejam muito interessantes, com um bom potencial de mercado, deve-se destacar que a renda auferida pelas integrantes do EES (descontados todos os custos de produção) ainda é aquém do desejável, inferior à um salário mínimo por pessoa. Desse modo, a renda decorrente da atuação no EES é "encarada" enquanto um valor que complementa outras fontes de renda familiar das mulheres do EES. Não obstante, vale registrar que a renda obtida no EES foi descrita enquanto crucial em determinados momentos tais como o período de piracema, no qual as pessoas que trabalham diretamente com a pesca profissional no município ficam impedidas, legalmente, de exercer as suas atividades.

No que tange ao aspecto organizacional do EES, destaque-se que há uma diretoria formalmente constituída no empreendimento e "sacramentada" no estatuto da organização. A diretoria é composta por uma presidenta (e a respectiva vice), uma secretária, uma tesoureira e uma fiscal. Há tentativas de se conduzir reuniões regulares no EES, para que as decisões sejam coletivamente compartilhadas entre as pessoas. No entanto, a regularidade das reuniões, em muitos casos, esbarra na falta de tempo e na necessidade de se dedicar precipuamente às atividades de produção, em detrimento das assembleias e reuniões deliberativas no EES.

Portanto, dadas as características gerais brevemente descritas nos parágrafos anteriores, tem-se na figura 2 a nuvem de palavras decorrentes da sistematização, com o uso do software Iramuteq, dos principais termos (palavras) que foram recorrentes nos discursos das pessoas com as quais dialogamos no EES. 
Figura 2 - Nuvem de palavras decorrentes da sistematização das entrevistas no EES

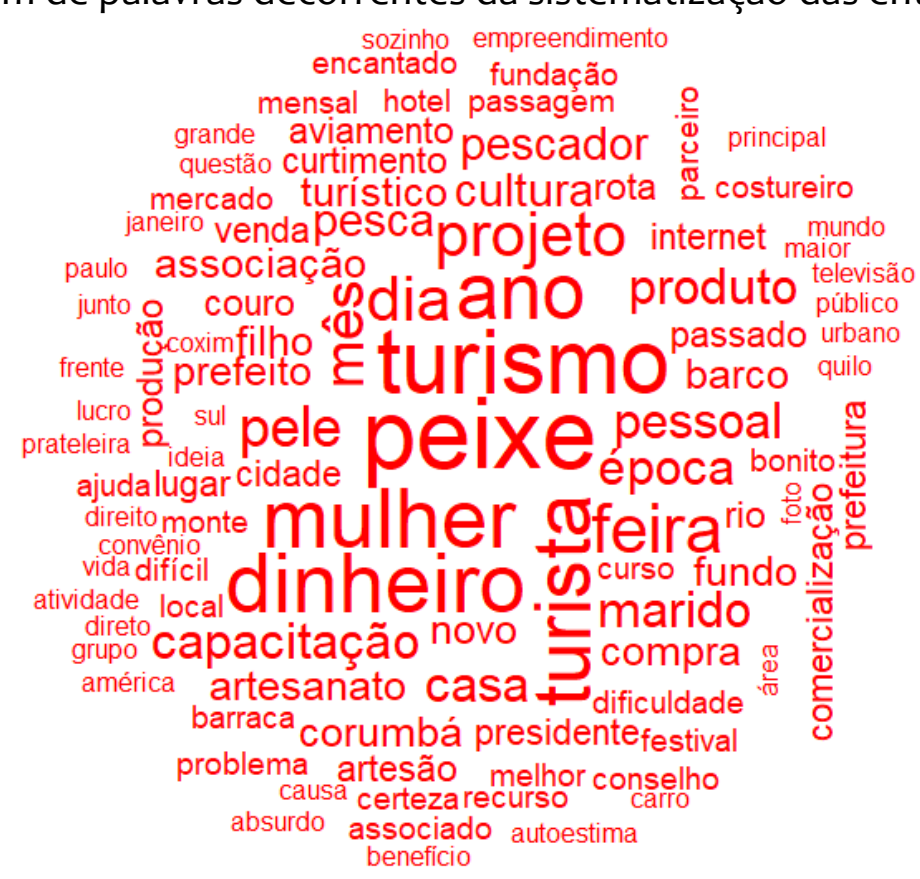

Fonte: Elaborado pelos autores, por meio do Iramuteq

Da análise da nuvem de palavras do EES percebe-se que palavras evocadas em destaque são: peixe, turismo, mulher, feira, ano e dinheiro. Esta concentração de palavras relaciona-se diretamente ao contexto do empreendimento, inteiramente composto por mulheres, cujo enfoque é a produção de artesanatos a partir do couro do peixe, reforçando a importância da participação em feiras, a cada ano, para a obtenção do dinheiro como fonte de renda. Em segundo plano, as principais palavras evocadas são: capacitação, pele, artesanato, produto, projeto e pesca, permitindo compreender que, embora algumas integrantes do empreendimento tenham conhecimento empírico sobre pesca e cuidados com a pele do peixe, o empreendimento demandou capacitação sobre o tratamento adequado do couro, contribuindo para as atividades características do projeto.

Ao se recorrer à figura 2, percebe-se que o turismo é algo recorrente na "fala" das pessoas com as quais interagimos no EES. Porém, como o turismo, sobretudo aquele com viés comunitário, insere-se na lógica de atuação do EES? No subtópico há um esforço de se lançar luz, definitivamente, nesta questão.

\subsection{Como o turismo comunitário "se insere" na lógica e atuação do EES estudado?}

A julgar pela ênfase do termo "turismo" na nuvem de palavras da figura 2, percebe-se que as integrantes do EES (re)conhecem a atividade do turismo no território de Corumbá enquanto algo que, de alguma forma, impacta no cotidiano do EES e no conjunto de crenças e percepções das pessoas com as quais estabelecemos interações no âmbito desta pesquisa.

Logo no começo das menções acerca da realidade do turismo em Corumbá, e do modo como tal atividade impacta o EES, as entrevistadas relataram que parte das vendas dos produtos é feita para turistas que de alguma forma descobriram, por intermédio de algum conhecido, a existência do empreendimento e as 
características dos produtos comercializados. De todo modo, há uma ênfase no fato de que esse tipo de venda ainda é muito pequeno em relação ao potencial que poderia se materializar caso o EES fosse efetivamente inserido na dinâmica do turismo no território.

Vale reiterar que há menções muito enfáticas de que o EES, à ótica das entrevistadas, não está inserido nas estratégias e nas políticas públicas de fomento ao turismo no território - incluindo o turismo de pesca, mais especificamente. Segundo a presidenta do EES, houve há alguns anos um esforço (que mostrou-se infrutífero, na prática), por parte da diretoria do EES, em dialogar com a Secretaria de Turismo do município de Corumbá, bem como com a Fundação de Cultura do Estado de Mato Grosso do Sul, tendo como escopo a inserção da Casa do Artesão de Corumbá (CAC) nos roteiros turísticos da cidade - porém, os gestores públicos à época não se mostraram muito adeptos à ideia, sobretudo em função da crença naturalizada de que o turismo de pesca é a grande força motriz da atração de visitantes para o território.

Para além do contato com os gestores públicos, a diretoria do EES também tentou estabelecer parcerias com o trade do turismo de pesca no território. Porém, as agências de turismo, hotéis e barco-hotéis mostraram-se pouco sensíveis à ideia manifestada pelo EES de, por exemplo, levar os turistas à CAC para conhecerem o empreendimento; ou mesmo para disponibilizarem os produtos do EES nas próprias agências, hotéis e barco-hotéis para que os turistas pudessem adquiri-los, caso assim o desejassem.

Desse modo, os relatos acima esmiuçados revelam que, a despeito de os princípios relacionados à solidariedade e cooperação serem característicos do EES, nota-se que os demais negócios do trade turístico do território, sem contar o próprio poder público, não norteiam as suas ações a partir desses princípios, numa dinâmica em que o EES acaba sendo colocado, quase que compulsoriamente, à margem dos fluxos e ciclos "tradicionais" do turismo em Corumbá.

Ao perguntarmos se as entrevistadas "se enxergam" enquanto um EES ligado ao turismo comunitário, foi curioso perceber que as respostas, a princípio, foram alusivas à realidade de que o EES ainda não está efetivamente na dinâmica do turismo comunitário no território - porém, à ótica das entrevistadas, o EES poderia se inserir ativamente nesse cenário, caso houvesse um conjunto de estratégias e políticas de estímulo à esse tipo de iniciativa.

Constatamos um conjunto de relatos de que o turismo potencialmente desenvolvido no EES seria um "turismo diferente", calcado em experiências mais autênticas, partindo dos princípios ligados à solidariedade, democracia, cooperação e autogestão, que são característicos do movimento de economia solidária e do segmento de turismo comunitário. Além disso, vale dizer que a lógica do turismo aqui considerado partiria da própria história e do "saber-fazer" das mulheres que corporificam o EES estudado.

Dentre os potenciais produtos turísticos que poderiam decorrer das experiências de turismo comunitário no âmbito do EES, tem-se as seguintes possibilidades (de acordo com as entrevistadas neste estudo):

(I) Atividades de visitação às dependências do EES, na qual o turista poderia conhecer o processo produtivo dos artesanatos à base do couro de peixe; 
(II) Realização de oficinas em grupo, na qual seriam ensinadas, pelas próprias integrantes do EES, algumas técnicas de curtimento, corte e costura do couro do peixe. Tais oficinas poderiam ser especialmente direcionadas para um público da terceira idade, que no geral identifica-se com atividades artesanais, além de que apreciaria a possibilidade de estabelecer diálogos e interações com outras pessoas;

(III) Condução de rodas de conversa e contação de histórias, nas quais seriam explicitadas as próprias trajetórias das integrantes do EES - que são mulheres corumbaenses, diretamente ligadas à atividade da pesca e, portanto, com uma relação muito íntima com o "modo de vida da/o pantaneira/o";

(IV) Produção e comercialização de produtos gastronômicos, sobretudo ligados a preparações que levam peixe na receita - a grande maioria das mulheres alegou conhecer receitas muito peculiares, típicas da gastronomia na região pantaneira. Tais receitas perfazem um exercício de se contar a história do pantanal e da mulher pantaneira por intermédio da comida, uma vez que muitas preparações são típicas, não raro ensinadas pelas mães e avós das entrevistadas;

(V) Atividades de contação de histórias relacionadas à Casa do Artesão de Corumbá (CAC), local em que está sediado o EES sob análise e que, no passado, abrigou uma cadeia pública do município. Deve-se salientar, por ser oportuno, que o prédio do CAC é belo, muito chamativo e bem localizado, muito embora esteja atualmente em estado relativamente precário de conservação.

Desse modo, os relatos acima esmiuçados, acerca dos produtos do turismo comunitário que pode ser desenvolvido no EES revelam uma possibilidade de se recuperar a história do empreendimento, além do expediente da valorização da cultura e da identidade das pessoas que desenvolvem as atividades de produção e comercialização no EES.

Não obstante, vale considerar que a própria "razão de ser" do EES estudado traz no seu âmago a questão do reaproveitamento de um insumo (o couro do peixe), que em outra ocasião seria descartado. Nesse ínterim, vale salientar que o turismo comunitário potencialmente implementado no âmbito do empreendimento estudado poderia, naturalmente, enquadrar-se nos princípios da sustentabilidade socioambiental, que é valor muito importante para as iniciativas de turismo comunitário, conforme realçaram Grimm e Sampaio (2016), já citados ao longo deste estudo, no referencial teórico.

É uma demanda recorrente, no discurso das nossas entrevistadas, o desejo de que sejam criadas novas rotas de turismo em Corumbá. Em síntese, tais rotas incorporariam a perspectiva do turismo de base comunitária, realçando o potencial cultural, histórico, arquitetônico, étnico e até mesmo ambiental do território corumbaense.

Ademais, ficou evidenciada, no discurso das mulheres do EES, uma crítica muito contundente em relação ao modo como o turismo de pesca é operacionalizado no município. Tal crítica decorre da baixa capacidade desse tipo de turismo em "entregar" maiores e melhores oportunidades para o território, empoderando grupos específicos - tais como as mulheres do EES investigado -, e gerando ocupação e renda para uma miríade maior de pessoas do território. 
Destaque-se também que, no entender das nossas entrevistadas, o turismo de pesca traz consequências negativas ao território, em termos socioambientais e econômicos, sobretudo porque: (I) consome de modo intensivo os recursos ambientais e pesqueiros da localidade, dificultando a atividade da pesca profissional (que é fonte de sustento para um contingente significativo de pessoas no pantanal sul-mato-grossense - incluindo as próprias famílias das mulheres com as quais dialogamos); (II) é conduzido por um pequeno grupo de empresários do município, não raro sob a forma de verdadeiros oligopólios e; (III) não contribui para a melhoria da qualidade de vida das pessoas historicamente subalternizadas do território.

Aliás, sobre o último ponto citado no parágrafo anterior (item III), percebemos no discurso das nossas entrevistadas um conjunto de relatos de que as pessoas que prestam serviços ao turismo de pesca (sob a forma de guias, cozinheiros, ajudantes e condutores das embarcações) recebem baixas remunerações e, em sua grande maioria, não possuem registro formal de trabalho. Não obstante, mesmo que de modo muito evasivo e escorregadio, constatamos que em muitas circunstâncias o turismo de pesca no território acaba por fomentar atividades e práticas quase nada desejáveis, tais como: o descaminho de produtos adquiridos na Bolívia (cujo acesso é muito fácil, inclusive pelo próprio Rio Paraguai), o consumo de entorpecentes, além de atividades ligadas à prostituição.

Ao indagarmos as nossas entrevistadas sobre os potenciais impactos, sejam positivos ou negativos, do turismo comunitário no território (o que incluiria impactos potenciais do próprio EES, caso se inserisse ativamente neste segmento), percebemos relatos muito contundentes que dão conta de que: (I) o turismo comunitário poderia gerar renda e ocupação de modo mais equilibrado e fraterno às pessoas mais simples e vulneráveis do território; (II) tal modalidade de turismo valorizaria outros elementos do território, para além do seu potencial pesqueiro; (III) o turismo comunitário poderia permitir um empoderamento de grupos específicos - tais como as mulheres do EES estudado neste artigo e; (IV) o turismo comunitário (re)significaria a ênfase que o próprio poder público local e regional possui de que o turismo de pesca é a grande força motriz da atração de visitantes para o território.

Portanto, os dados esmiuçados nos parágrafos anteriores revelam que o turismo comunitário é compreendido, no âmbito do EES estudado, enquanto uma atividade com interessantes potenciais, desde que seja fomentada no território, inclusive pelo conjunto de políticas públicas. Ainda que o turismo comunitário não seja, por ora, uma realidade no EES investigado, vale salientar o interesse manifestado pelas pessoas com as quais dialogamos de se inserirem ativamente neste segmento, a partir dos princípios da solidariedade, cooperação, democracia e autogestão, que também são caracterizadores do movimento de economia solidária.

\section{Considerações finais}

Afinal, de que modo a perspectiva do turismo de base comunitária é compreendida e, eventualmente, implementada pelo EES estudado neste artigo? 
Em síntese, os dados que foram coletados e sistematizados neste estudo permitem inferir que o turismo de base comunitária é compreendido no EES enquanto uma atividade factível e com muito potencial para a geração de ocupação e renda às pessoas do empreendimento. Ademais, o turismo de base comunitária é "encarado" enquanto uma atividade que pode permitir a manutenção da identidade e das especificidades socioculturais das mulheres envolvidas no EES, numa dinâmica em que a solidariedade, cooperação e democracia seriam a tônica do potencial "fazer turístico" na organização em análise.

Muito embora o turismo comunitário ainda não seja, stricto sensu, uma realidade já evidenciada no EES analisado, vale dizer que foi perceptível, ao longo das nossas entrevistas, o desejo das pessoas do empreendimento em envolverem-se com esse tipo de atividade. Não obstante, as próprias entrevistadas reconheceram que uma série de elementos da atividade do EES, além da própria história, modo de vida e cultura das pessoas do empreendimento, podem constituir produtos do turismo comunitário desenvolvimento no âmbito da organização sob estudo.

Ressalte-se que, a partir da Análise Crítica do Discurso ( $A C D$ ) empreendida ao longo da avaliação dos resultados do artigo, foi possível constatar que todo o aparato perceptivo e o conjunto de crenças das pessoas do EES estudado estão ligadas às seguintes questões:

(I) Há uma crença muito consolidada de que o poder público local e regional é omisso em estabelecer estratégias e políticas que amparem o EES, inclusive no interesse manifestado pelo empreendimento em potencialmente envolver-se com atividades ligadas ao turismo de base comunitária;

(II) Verificou-se uma percepção muito forte de que as empresas do trade turístico local, majoritariamente ligadas ao turismo de pesca, são avessas à possibilidade de integrar o EES nos fluxos e roteiros já existentes no município;

(III) As pessoas do EES são muito convictas de que o turismo comunitário no âmbito do empreendimento é algo muito factível, que encontraria uma sinergia deveras forte em relação às atividades já desenvolvidas, atualmente, no EES;

(IV) Há uma crença de que o turismo comunitário não destituiria o empreendimento dos princípios ligados à economia solidária, majoritariamente no que tange ao exercício da solidariedade, cooperação e autogestão do EES. Aliás, vale dizer que o turismo comunitário foi visto como um campo de possibilidades para a valorização da cultura e da identidade das pessoas inseridas no EES e;

(V) Por fim, deve-se ressaltar que há uma demanda muito contundente para que sejam criados novos roteiros e/ou possibilidades de se "fazer turismo" em Corumbá, que notadamente contemplem as iniciativas ligadas ao turismo comunitário e à economia solidária.

É notório que as principais inferências deste estudo devem ser "lidas" com ressalvas, já que as reflexões aqui conduzidas partiram de um estudo de caso. Nesse ínterim, esta constatação é uma das limitações mais evidentes deste estudo (calcarse em um estudo de caso).

Porém, vale dizer que o presente estudo de caso possui o mérito e a relevância em apontar que o turismo comunitário pode, sim, constituir um campo de possibilidades muito profícuo e interessante para os EES, desde que haja uma sensibilidade, sobretudo por parte do poder público e dos demais integrantes das cadeias de produção do turismo, em apoiar esse tipo de iniciativa, tendo como 
O turismo de base comunitária no contexto de um empreendimento econômico solidário no Pantanal de Mato Grosso do Sul

escopo tornar as experiências turísticas mais autênticas, solidárias, cooperativas e fraternas.

\section{REFERÊNCIAS}

ARRUDA, D. O.; MARIANI, M. A. P. A construção dos fundamentos conceituais da economia solidária. Política \& Sociedade: Revista de Sociologia Política, v. 12, n. 25, p. 99-129, 2014. https://doi.org/10.5007/2175-7984.2013v12n25p99

ARRUDA, D. O.; MARIANI, M. A. P.; FISCHER, R. M. Economia solidária, turismo e desenvolvimento local: algumas reflexões aplicadas ao contexto de Corumbá, Mato Grosso do Sul. In: THOMAZ, R. C.; MARIANI, M. A. P.; MORETTI, E. C.; ARRUDA, D. O. (Orgs.). Turismo, políticas e dinâmicas no espaço rural. Campo Grande: Ed. UFMS, 2013 p. $183-208$.

ASSIS, G. C.; PEIXOTO, R. C. O turismo é uma dádiva? Uma "etnografia das trocas" e a oferta da experiência "chamada" Turismo de Base Comunitária em Anã/Santarém/Pará. Revista Brasileira de Pesquisa em Turismo, v. 13, n. 2, p. 144160, 2019. https://doi.org/10.7784/rbtur.v13i2.1568

BARTHOLO, R. Sobre o sentido da proximidade: implicações para um turismo situado de base comunitária. In: BARTHOLO, R.; SANSOLO, D. G.; BURSZTYN, I. (Orgs.). Turismo de Base Comunitária: diversidade de olhares e experiências brasileiras. Rio de Janeiro: Letra e Imagem, 2009. p. 45-54.

BARTHOLO, R.; SANSOLO, D. G.; BURSZTYN, I. Turismo de base comunitária: diversidade de olhares e experiências brasileiras. Rio de Janeiro: Letra e Imagem, 2009.

BENI, M. C. Saturação e rejeição ao turismo nas destinações turísticas. Revista Brasileira de Pesquisa em Turismo - RBTUR, v. 14, n. 2, p. 1-8, 2020. https://doi.org/10.7784/rbtur.v14i2.1847

BRASIL. Dinâmica e diversidade do turismo de base comunitária: desafio para a formulação de política pública. Brasília, DF: Ministério do Turismo, 2010. 88 p. (Relatório Técnico).

BURGOS, A.; MERTENS, F. As redes de colaboração no turismo de base comunitária: implicações para a gestão participativa. Tourism \& Management Studies, v. 12, n. 2, p. 18-27, 2016. http://dx.doi.org/10.18089/tms.2016.12203

CÂMARA DOS DEPUTADOS. Câmara aprova título de capital do Pantanal a Corumbá. 2008. Disponível em: https://www.camara.leg.br/noticias/115038CAMARA-APROVA-TITULO-DE-CAPITAL-DO-PANTANAL-A-CORUMBA. Acesso em: 10 mar. 2020. 
CHARTIER, J. F.; MEUNIER, J. G. Text mining methods for social representation analysis in Large Corpora. Papers on Social Representations, v. 20, n. 2, p. 1-47, 2011.

COLLIS, J.; HUSSEY, R. Pesquisa em administração: um guia prático para alunos de graduação e pós-graduação. $2^{\mathrm{a}}$. ed. Porto Alegre, RS: Bookman, 2005.

CONTI, B. R.; ANTUNES, D. C. Turismo e economia solidária: uma aproximação relutante. Rosa dos Ventos - Turismo e Hospitalidade, v. 12, n. 1, p. 106-128, 2020. http://dx.doi.org/10.18226/21789061.v12i1p106

CONTI, B. R.; ROCHA, L. R. V. G.; VITEZE, N. N. As conexões entre a economia solidária e o turismo de base comunitária no estado do Rio de Janeiro. Revista Acadêmica Observatório de Inovação do Turismo, v. 12, n. 2, p. 1-21, 2018.

CORIOLANO, L. N.; VASCONCELOS, F. P. Região, desenvolvimento regional e turismo comunitário. Revista Brasileira de Desenvolvimento Regional, v. 1, n. 1, p. 95-111, 2013. http://dx.doi.org/10.7867/2317-5443.2013v1n1po95-111

CRESWELL, J. W. Projeto de pesquisa: métodos qualitativo, quantitativo e misto. $3^{\mathrm{a}}$. ed. Porto Alegre, RS: Artmed, 2010.

DNIT - Departamento Nacional de Infraestrutura de Transportes. 2018. Hidrovia do Paraguai. Disponível em: http://www.dnit.gov.br/modais-2/aquaviario/hidrovia-doparaguai. Acesso em: 11 mar. 2020.

FABRINO, N. H.; NASCIMENTO, E. P.; COSTA, H. A. Turismo de Base Comunitária: uma reflexão sobre seus conceitos e práticas. Caderno Virtual de Turismo, v. 16, n. 3, p. 172-90, 2016.

FAGUNDES, M. B. B.; SCHMIDT, V.; CENTURIÃO, D. S. A. Identificação das variáveis de SWOT como ferramenta para promover o diagnóstico turístico e o desenvolvimento local: Corumbá-MS. Informe GEPEC, v. 17, n. 1, p. 6-22, 2013.

FRANÇA FILHO, G. C.; LAVILLE, J. Economia solidária: uma abordagem internacional. Porto Alegre, RS: Ed. UFRGS, 2006.

GAIGER, L. I. G. A economia solidária diante do modo de produção capitalista. Caderno CRH, v. 16, n. 39, p. 181-211, 2003.http://dx.doi.org/10.9771/ccrh.v16i39.18642

GAIGER, L. I. G. A racionalidade dos formatos produtivos autogestionários. Revista Sociedade e Estado, v. 21, n. 2, p. 513-545, 2006. https://doi.org/10.1590/S010269922006000200009

GAIGER, L. I. G.; KUYVEN, P. S. Economia solidária e trajetórias de trabalho: uma visão retrospectiva a partir de dados nacionais. Revista Brasileira de Ciências Sociais, v. 35, n. 103, p. 1-18, 2020. https://doi.org/10.1590/3510304/2020 
O turismo de base comunitária no contexto de um empreendimento econômico solidário no Pantanal de Mato Grosso do Sul

GIAMPICCOLI, A.; MTAPURI, O. Between theory and practice: a conceptualization of community-based tourism and community participation. Loyola Journal of Social

Sciences, v. 29, n. 1, p. 27-52, 2015.

GOULART, J. O.; MARIN, T. R. Políticas públicas de Economia Solidária e a SENAES: um balanço preliminar (2003-2006). Revista Otra Economía, v. 5, n. 8, p. 48-58, 2011. https://doi.org/10.4013/otra.2011.58.04

GRIMM, I. J.; SAMPAIO, C. A. C. Turismo comunitário: possibilidade de adaptação diante das mudanças ambientais e climáticas. Caderno Virtual de Turismo, v. 16, n. 2, p. 62-78, ago. 2016.

HIGGINS-DESBIOLLES, F. Justice tourism and alternative globalization. Journal of Sustainable Tourism, v. 16, n. 3, p. 345-364, 2008.

HILLENKAMP, I. As Outras Economias à Luz do Gênero. Revista Otra Economía, v. 12, n. 22, p. 80-90, 2019.

OLIVEIRA, A. P.; SANTOS, B. P. C. Turismo de Base Comunitária na Amazônia Legal brasileira: organização da atividade ou estratégia de marketing? Revista Brasileira de Ecoturismo - RBECOTUR, v. 12, n. 4, p. 488-505, 2019. https://doi.org/10.34024/rbecotur.2019.v12.6787

IBGE - Instituto Brasileiro de Geografia e Estatística. IBGE cidades - Corumbá, MS. 2019. Disponível em: https://cidades.ibge.gov.br/brasil/ms/corumba/panorama. Acesso em: 2 mar. 2020.

IPEA - Instituto de Pesquisa Econômica Aplicada. Os novos dados do mapeamento de economia solidária no Brasil: nota metodológica e análise das dimensões socioestruturais dos empreendimentos. Brasília, DF: IPEA, 2016. 41 p. (Relatório de Pesquisa).

LAVILLE, J. L. Do século 19 ao século 21: permanência e transformações da solidariedade em economia. Revista Katálysis, v. 11, n. 1, p. 20-42, 2008. https://doi.org/10.1590/\%25x

LIMA, J. C. O trabalho autogestionário em cooperativas de produção: o paradigma revisitado. Revista Brasileira de Ciências Sociais, v. 19, n. 56, p. 45-62, 2004. https://doi.org/10.1590/S0102-69092004000300004

LIMA, R. P. Turismo de base comunitária como inovação social. 2011. 191f. Tese (Doutorado em Engenharia de Produção) - Universidade Federal do Rio de Janeiro (UFRJ), Rio de Janeiro, 2011.

MACHADO, R. X.; COSTA, E. A. O turismo de pesca em Corumbá, na fronteira Oeste do Brasil. Revista Iberoamericana de Turismo - RITUR, v. 7, n. 1, p. 36-48, 2017. https://doi.org/10.2436/20.8070.01.77 
MANO, A. D.; MAYER, V. F.; FRATUCCI, A. C. Community-based Tourism in Santa Marta Favela/RJ: social, economic and cultural opportunities. Revista Brasileira de Pesquisa em Turismo, v. 11, n. 3, p. 413-435, 2017.

https://doi.org/10.7784/rbtur.v11i3.1314

MAZA, M. T. R. Trabajadoras rurales chiapanecas y relaciones sociales en la producción: ¿hacia una economía solidaria? Revista Otra Economía, v. 10, n. 19, p. 150-163, 2016. https://doi.org/10.4013/otra.2016.1019.02

MIELKE, E. J. C.; PEGAS, F. V. Turismo de base comunitária no Brasil. Insustentabilidade é uma questão de gestão. Revista Turismo em Análise, v. 24, n. 1, p. 170-189, 2013. https://doi.org/10.11606/issn.1984-4867.v24i1p170-189

OLIVEIRA, L. D.; PINHEIRO, L. E. L.; MICHELS, I. L.; BRUM, E. A organização da atividade turística em Corumbá, sob o enfoque dos conceitos de cadeia produtiva e arranjo produtivo local. Pasos - Revista de Turismo y Patromonio Cultural, v. 6, n. 3, p. 511-522, 2008.

PADILHA, M. I. C. S.; RAMOS, F. R. S.; BORENSTEIN, M. S.; MARTINS, C. R. A responsabilidade do pesquisador ou sobre o que dizemos acerca da ética em pesquisa. Texto \& Contexto - Enfermagem, v. 14, n. 1, p. 96-105, 2005. https://doi.org/10.1590/S0104-07072005000100013.

SILVA, J. P.; JESUS, P.; FONSECA, J. M. Turismo, economia solidária e inclusão social em Porto de Galinhas, PE. Caderno Virtual de Turismo, v. 11, n. 3, p. 325-340, 2011.

SINGER, P. Introdução à economia solidária. São Paulo, SP: Fundação Perseu Abramo, 2002.

SPIVAK, G. Pode o subalterno falar? Belo Horizonte: Ed. UFMG, 2010.

VAN DIJK, T. A. Communicating racism: Ethnic prejudice in thought and talk. Newbury Park, CA: Sage Publications, 1987.

VAN DIJK, T. A. Ideology: A multidisciplinary approach. London, UK: Sage Publications, 1998.

VAN DIJK, T. A. Macrostructures: An interdisciplinary study of global structures in discourse, interaction, and cognition. Hillsdale, NJ: Erlbaum, 1980.

ZAOUAL, H. Do turismo de massa ao turismo situado: quais as transições? Caderno Virtual de Turismo, v. 8, n. 2, p. 1-14, 2008. 
O turismo de base comunitária no contexto de um empreendimento econômico solidário no Pantanal de Mato Grosso do Sul

Milton Augusto Pasquotto Mariani. Possui doutorado em Geografia Humana pela Universidade de São Paulo (USP) e pós-doutorado em Administração, também pela USP. Atualmente, é professor do quadro permanente da Universidade Federal de Mato Grosso do Sul (UFMS), credenciado nos Programas de Pós-Graduação em Administração (PPGAD) e Estudos Fronteiriços (PPGEF) da instituição. Endereço: Av. Sen. Filinto Müler, n. 1555 (Cidade Universitária), Vila Ipiranga - CEP: 79074-460 - Campo Grande, MS, Brasil. E-mail: miltmari@terra.com.br

Bruno Diego Alcantara Cardozo. Possui mestrado em Administração pela Universidade Federal de Mato Grosso do Sul (UFMS). Endereço: Av. Sen. Filinto Müler, n. 1555 (Cidade Universitária), Vila Ipiranga - CEP: 79074-460 - Campo Grande, MS, Brasil. E-mail: brunodiegocardozo@gmail.com

Dyego de Oliveira Arruda. Possui doutorado em Administração de Organizações pela Universidade de São Paulo (USP) e pós-doutorado em Administração pela Universidade Federal de Mato Grosso do Sul (UFMS). Atualmente, é professor do quadro permanente do Centro Federal de Educação Tecnológica Celso Suckow da Fonseca (CEFET), credenciado no Programa de Pós-Graduação em Relações Étnico-Raciais (PPRER) da instituição. Endereço: Rua Voluntários da Pátria, n. 30 (Prédio do CEFET/RJ), Bairro Belo Horizonte - CEP: 27600-000 - Valença, RJ, Brasil. E-mail: dyego.arruda@gmail.com

Maurílio Barbosa de Oliveira da Silva. É doutorando em Administração pela Universidade Estadual de Campinas (Unicamp). Possui mestrado em Administração pela Universidade Federal de Mato Grosso do Sul (UFMS). Endereço: Rua Pedro Zaccaria, n. 1300 (FCA-Unicamp) - CEP: 13484-350 - Limeira, SP, Brasil. E-mail: barbosamaurilio@hotmail.com

Como citar: MARIANI, Milton Augusto Pasquotto et al. O turismo de base comunitária no contexto de um empreendimento econômico solidário no Pantanal de Mato Grosso do Sul. Redes (St. Cruz Sul, Online), Santa Cruz do Sul, v. 25, p. 2407-2431, 2020. ISSN 19826745. doi:https://doi.org/10.17058/redes.v25i0.14878.

\section{CONTRIBUIÇÃO DE CADA AUTOR}

Conceituação (Conceptualization): Milton Augusto Pasquotto Mariani, Bruno Diego Alcantara Cardozo, Dyego de Oliveira Arruda e Maurílio Barbosa de Oliveira da Silva. Curadoria de Dados (Data curation): Bruno Diego Alcantara Cardozo e Dyego de Oliveira Arruda.

Análise Formal (Formal analysis): Milton Augusto Pasquotto Mariani, Bruno Diego Alcantara Cardozo, Dyego de Oliveira Arruda e Maurílio Barbosa de Oliveira da Silva.

Obtenção de Financiamento (Funding acquisition): Não se aplica. 
Investigação/Pesquisa (Investigation): Milton Augusto Pasquotto Mariani, Bruno Diego Alcantara Cardozo e Dyego de Oliveira Arruda.

Metodologia (Methodology): Milton Augusto Pasquotto Mariani, Bruno Diego Alcantara Cardozo, Dyego de Oliveira Arruda e Maurílio Barbosa de Oliveira da Silva.

Administração do Projeto (Project administration): Milton Augusto Pasquotto Mariani, Bruno Diego Alcantara Cardozo e Dyego de Oliveira Arruda.

Recursos (Resources): Milton Augusto Pasquotto Mariani, Bruno Diego Alcantara Cardozo, Dyego de Oliveira Arruda e Maurílio Barbosa de Oliveira da Silva.

Software: Maurílio Barbosa de Oliveira da Silva.

Supervisão/orientação (Supervision): Milton Augusto P. Mariani e Dyego de Oliveira Arruda Validação (Validation): Milton Augusto Pasquotto Mariani, Bruno Diego Alcantara Cardozo, Dyego de Oliveira Arruda e Maurílio Barbosa de Oliveira da Silva.

Visualização (Visualization): Milton Augusto Pasquotto Mariani, Bruno Diego Alcantara Cardozo, Dyego de Oliveira Arruda e Maurílio Barbosa de Oliveira da Silva.

Escrita - Primeira Redação (Writing - original draft): Bruno Diego Alcantara Cardozo e Maurilio Barbosa de Oliveira da Silva.

Escrita - Revisão e Edição (Writing - review \& editing): Milton Augusto Pasquotto Mariani e Dyego de Oliveira Arruda

Fontes de fomento: O presente trabalho foi realizado com apoio da Fundação Universidade Federal de Mato Grosso do Sul - UFMS/MEC - Brasil; e do Centro Federal de Educação Tecnológica Celso Suckow da Fonseca - CEFET-RJ/MEC - Brasil 